\title{
The Effect of Vibration Impact from Piling Works to the Surrounding Buildings
}

\author{
Nurulzatushima Abdul Karim ${ }^{1, *}$, Adhilla Ainun Musir ${ }^{1}$, Mohd Samsudin Abdul Hamid, \\ Siti Hafizan Hassan ${ }^{1}$, Ahmad Ihsan Qistan Kamarulzaman ${ }^{1}$, Mohd Farid Ahmad Majid ${ }^{2}$
${ }^{1}$ School of Civil Engineering, College of Engineering, Universiti Teknologi MARA, Cawangan Pulau Pinang, Kampus Permatang Pauh, 13500 Pulau Pinang, Malaysia
${ }^{2}$ Farid Ahmad Consulting Engineers Sdn. Bhd., No. 8-2 (2 ${ }^{\text {nd }}$ Floor), Jalan Puteri 2A/1, Bandar Puteri Bangi, 4300 Kajang, \\ Selangor Darul Ehsan, Malaysia
}

Received February 14, 2021; Revised July 26, 2021; Accepted August 15, 2021

\section{Cite This Paper in the following Citation Styles}

(a): [1] Nurulzatushima Abdul Karim, Adhilla Ainun Musir, Mohd Samsudin Abdul Hamid, Siti Hafizan Hassan, Ahmad Ihsan Qistan Kamarulzaman, Mohd Farid Ahmad Majid, "The Effect of Vibration Impact from Piling Works to the Surrounding Buildings," Civil Engineering and Architecture, Vol. 9, No. 5A, pp. 101 - 107, 2021. DOI: 10.13189/cea.2021.091312.

(b): Nurulzatushima Abdul Karim, Adhilla Ainun Musir, Mohd Samsudin Abdul Hamid, Siti Hafizan Hassan, Ahmad Ihsan Qistan Kamarulzaman, Mohd Farid Ahmad Majid (2021). The Effect of Vibration Impact from Piling Works to the Surrounding Buildings. Civil Engineering and Architecture, 9(5A), 101 - 107. DOI: 10.13189/cea.2021.091312.

Copyright $\bigcirc 2021$ by authors, all rights reserved. Authors agree that this article remains permanently open access under the terms of the Creative Commons Attribution License 4.0 International License

\begin{abstract}
Construction activities such as dynamic compaction, pile-driving, and any site activities heavy construction equipment can generate ground and structure vibration. Vibration may cause damage to nearby structures. As the current construction works are frequently located in urban areas where the distance between the nearest building structures to the construction site is not far. Therefore, this paper studied the effect of vibration produced from piling work to the nearest existing building and determination of limits in term of allowable vibration and distance limit between piling work and existing structure. An accelerometer was used to collect the vibration data from the piling activities and the data were analysed by using Microsoft Excel. The findings of the study presented several vibrations and limits based on several guidelines. The study stated not disobeying the proposed guidelines may harm and damage the existing structure. This research contributes to future development to ensure the future construction does not exceed the limit as stated in the guideline to avoid any type of damage to the existing structure. Thus, any project in the future should take into consideration the effect of vibration and the distance limit to reduce the effect of vibration from the construction site to the surrounding structures.
\end{abstract}

Keywords Pile Vibration, Vibration Impact, Driven
Pile, Structural Vibration, Structure Damage

\section{Introduction}

Construction operations involve various sources of vibrations such as blasting, pile driving, dynamic compaction of weak soils, and others [1]. The execution of construction projects near the existing structures can create additional problems which lead to disturbance of some businesses, possible structural damage, and disruption or annoyance to the people surrounding [2]. Ground vibrations that were caused by the vibration source may cause damage to the existing structure when the excitation of frequency does not match with the natural frequency of the structure. Vibration can be regarded within a distance equal to the final excavation depth in rock (close-in blasting) or one pile length from a pile driven. The distance can be substantially larger for sensitive structures. The intensity of structural vibrations depends on soil-structure interaction. According to Bayraktar [1], direct minor and major structural damage without resonant structural responses were observed in the velocity $33-191 \mathrm{~mm} / \mathrm{s}$ range for frequencies of 2 to $5 \mathrm{~Hz}$ 
and the velocity $102-254 \mathrm{~mm} / \mathrm{s}$ range for frequencies of 60 to $450 \mathrm{~Hz}$. However, in a real construction site, the actual vibrations that were measured were often below the guided velocity values and higher than the USBM vibration limits. Distances of close to 200 and $500 \mathrm{~m}$ from dynamic sources are demonstrated in [3]. A study by Deckner [4] approved that the vibration can harm the surrounding. It is also approved that the vibration leads to damaging the structure, disturbed occupants, and suspension of the construction work. This study is important to avoid fraudulent claims and for regulatory compliance and to maintain the public relationship. If a negative impact occurs, the unnecessarily conservative estimations will increase the cost, may limit the choice of construction method, and delay the project. This study is developed to analyse the relationship between vibration with the distance between the pile point to column structure.

\section{Literature Review}

Vibrations from construction works can generate body and surface waves into the soil medium. The body waves will transmit through soil and rock. Two types of body waves are compression and shear waves that should be taken into consideration at a relatively short or small distance from the site of construction. Rayleigh Waves are a type of surface acoustic waves that travel along a surface of solids. Most structural engineers have considerable practical interest in Rayleigh waves because building foundations are generally placed near the ground surface [1]. Ground vibration from piling works may affect nearby existing structures in several different ways. The deformation of elastic and plastic soil cause dissimilar structural responses and damage. Generally, ground vibrations were measured in three orthogonal directions which commonly are means of acceleration in the vertical, transverse and longitudinal directions. The most common unit use for structural damage caused by vibration is peak particle velocity (PPV) and is generally taken as the vector sum of these three orthogonal directions components [5].

\subsection{Effect of Vibrations}

Ground vibrations that were generated from the vibration source may cause direct impact to the existing structure when the excitation of frequency did not match with the natural frequency of the structure Structural vibrations and condition of resonance can be generated thru the proximity of the dominant frequency of any ground vibration produce to one of building's natural frequency. The condition of resonance can be detected at about of few hundred metres from the site of piling works and even more than one kilometre from a blasting site.
Examples of resonance in multi-storey buildings at distances of close to 200 and $500 \mathrm{~m}$ from dynamic sources are demonstrated in [3]. According to Svinkin [1], the frequency of $26 \mathrm{~Hz}$ from a vibratory sheet pile can generate ground vibrations below $5 \mathrm{~mm} / \mathrm{s}$ and vertical floors vibrations higher than $51 \mathrm{~mm} / \mathrm{s}$ for two-story houses which can cause architectural damage to the house.

However, several cases histories show no structural damage in the proximity of the dynamic sources with impact loads even possible for direct damage to structures. With different distances between vibration sources and structure, the direct vibration effects on the existing structure can occur due to the interaction of surface waves with different wavelengths and structures with diverse dimensions and stiffness. A surface wave will spread under the rigid structure foundations forms area with negative reactions from the elastic soil base that can change the contact between the existing nearby structure and the elastic soil base. This may cause the structure-soil system unstable. Besides that, the properties of these waves and structures can affect the reflection of the surface wave from a structure. The maximum effect matches the structure with variable stiffness while the minimum reflection may affect the rigid structure.

\subsection{Vibration Limits}

There are few sources of construction vibration. Below are the sources of construction vibrations:

a) Steady-state vibration or continuous vibration (vibratory pile drivers, compressors, large pumps, etc.).

b) Transient vibration or impact vibration (blasting, impact pile driving, demolition, etc.).

c) Pseudo-steady-state vibration (jackhammers, trucks, cranes, scrapers, etc.).

\subsection{Soil Settlement from Piles Driving and Construction Vibration}

Construction vibrations are a known nuisance and can damage existing structures if they are not properly monitored and accounted for. As a proactive means to mitigate vibration damage claims, nearby buildings should be inspected before and after construction and monitored during construction. The direct vibrations which a house and vibrations that affecting foundations soil will affect the house [6]. The installation of the pile in the sand may cause soil and settlement of structure due to the densification and liquefaction of vulnerable granular soils. According to M.E. Bayraktar [2] loose to medium dense sands with a relative density of less than $70 \%$ had been discovered in large settlements. From the result of the cone penetration test (CPT), relative density and soil classification of cohesionless soils can be derived. The derivation mostly has been employed highway projects for 
geotechnical investigation. Thus, it is expected that a dynamic settlement-prone soil layer might be reasonably identified if the CPT results for construction site soils are available. It is known that simple methods of estimating settlements in loose to medium dense sand during pile driving do not provide practical solutions. The prudent approach is moving forward with caution when the shape of the settlement is known to survive. For clay soil, it may be different from pile driving in sand. Pile penetration into clay soil may increase lateral stresses, pore pressures, and heaves of the ground surface. As the distance increases from the pile group area during pile driving, the excess pore pressure will also increase with each pile-driven and may reach large values. The excess pore pressure can be much larger than the initial effective overburden stress. Soil reconsolidates and the ground surface will settle after activities of pile-driven and the dissipation of the excess pore pressure is completed. The effect of the driven pile in soft to medium clay of the surrounding area supposedly can be expected. Distance from the installation of the pile can be expected equal to the thickness of the clay layer is penetrated.

\subsection{Pile Driving Impact}

\subsubsection{Machines and Components}

During the impact of pile driving, the impaction energy comes from striking of the hammer pile head with the downward impact velocity [7]. The energy from the hammer will transfer the blow impulses via the pile cap to the pile head. Some of the energy is damped by the pile cap and some is lost toward the contact area between the head of the pile and the cap of the pile. The impaction of the drivers can drive the piles into any type of soil. For the pile to penetrate the soil layer the static soil resistance must be overcome in the hammer blows thru the induced force blow for every blow of the pile, the pile is accelerated out of rest which means that the inertia and the shaft - and toe resistance must be overcome for each of the blow [8].

\subsubsection{Vibratory Pile Driving}

The vibratory driver will drive the pile into the soil with two mechanical actions which are vibratory action and stationary action. For vibratory action, it was to produce by the counter-rotating masses, while stationary action is by the weight of the hammer and also the weight of the pile itself (this static mass) [9]. The vibration prompts to development of the pore pressure and in the end liquefaction and a significant reduction of the static soil resistance. This is enabling the pile to penetrate the ground.

\subsection{Limit Distance between Buildings and Piling Points}

The vibration waves may propagate or travel in soil.
The waves may slightly reduce over distance as the waves travel thru the soil. As the waves travel farther than the vibration sources, the energy waves will reduce. According to Rockhill [9], the waves propagate as expanding rings, the energy per unit area of the wave decays in inverse ratio to the distance from the vibration source and the decay known as damping. This is because the damping is purely a part of the area surrounded by the wavefront as it spreads away from the source. There are many guidelines out there related to the distance of piling work points and the existing structure. One of the standards is Eurocode 3. In Eurocode 3, the distance is being categorized into the piling method which is the press-in method, drop hammer, and vibro hammer. In this research, the researchers are only focus on drop hammer. The distance limits are:

a) Architectural merit $-29.6 \mathrm{~m}$

b) Residential $-11.8 \mathrm{~m}$

c) Light commercial $-5.9 \mathrm{~m}$

d) Heavy industrial $-3.9 \mathrm{~m}$

e) Buried services $-2.9 \mathrm{~m}$

Based on the limit stated above, it is suitable to use in Malaysia since most of the guidelines used in Malaysia are Eurocode (EC) and British Standard (BS). Therefore, any project in Malaysia should follow this guideline to reduce any damage towards building near piling activities.

\section{Methodology}

The data collected at the construction site were vibration data, size of the pile, length of pile, the distance between the point of the pile with the affected building. The data used for the analysis were primary data collected at the construction site and secondary data from previous researchers. From the data collected, the data need to compare with the literature review collected from other researchers. Three pile points with different distances had been selected to analyse vibration with different distances. The data need to record in LabView Signal Express Software from before the pile pass through the mark $(5 \mathrm{ft}$. mark) until the mark passes away. The data recorded needs to be repeated until the last mark on the pile. The summary of data collection at the site is shown in Figure 1.

\subsection{Location of Case Study}

The location of this study was at Petronas Bandar Sunway that is located at 5494, Bandar Sunway, Jalan Todak 4, 13700 Seberang Jaya, Pulau Pinang. The Petronas is having a settlement problem on site.

Due to the settlement, the Petronas Owner decided to do reconstruction to avoid the problem becoming more serious. There are two existing buildings inside the site, which are KFC Sunway and Mesra (Petronas Mini Market). 


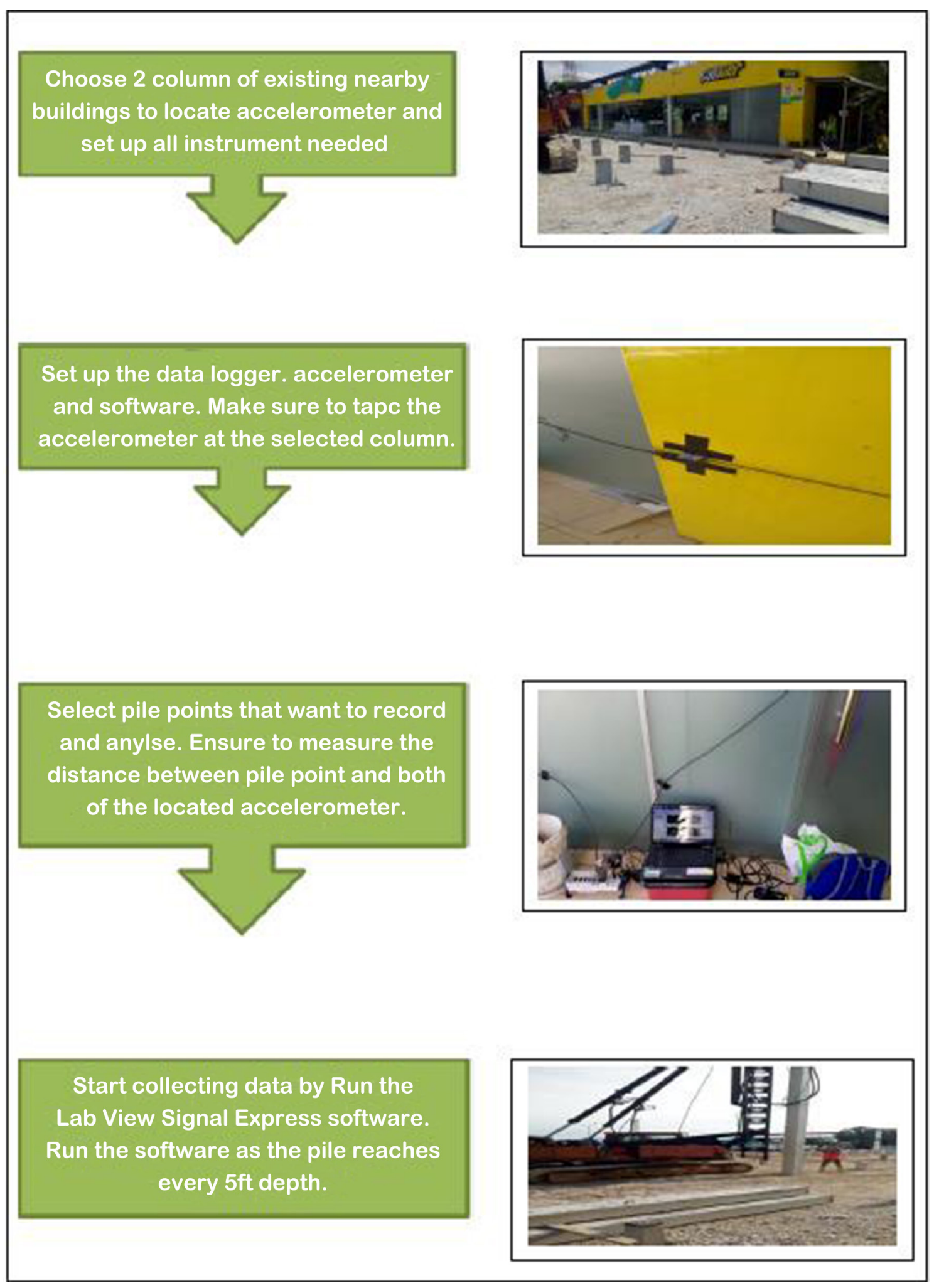

Figure 1. Summary of Data Collection at Site 


\section{Result}

The vibration generates during the piling installation was measured by using accelerometers LabView Signal Express soft installed in the construction site during the running of piling installation work. The distance between the points of the pile and the accelerometer was recorded.

The accelerometer and LabView Signal Express software are the instruments used to measure the vibration that is generated during piling installation at the construction site of Bandar Sunway Seberang Jaya. The result was recorded using LabView Signal Express Software and the recorded data were interpreted using Microsoft excel while the value of the vibration was chosen with the highest value for each point.

\subsection{Maximum Value of Vibration Data Collected}

Data were recorded for every 1.5 metres depth of pile and finished at the 25.5 metres of pile depth. The table below shows the highest value of vibration data for each 1.5 metres-depth. Table 1, Table 2, and Table 3 showed the vibration data that was collected from 3 piles points.

Figure 2 shows the vibration value of the front column face due to driven piling work from a nearby project site. The graphs plot based on the values of vibration that were tabulated in Table 1, 2, and 3.

Table 1. Maximum Values of Vibration Data Collected for 1st Pile Point

\begin{tabular}{cc}
\hline $\begin{array}{c}\text { Depth } \\
(\mathbf{m})\end{array}$ & $\begin{array}{c}\mathbf{1}^{\text {st }} \text { accelerometer-Front Column (g) (12.53m } \\
\text { distance accelerometer to point of pile work) }\end{array}$ \\
\hline 1.5 & 0.0268 \\
\hline 3 & 0.0205 \\
\hline 4.5 & 0.0243 \\
\hline 6 & 0.0122 \\
\hline 7.5 & 0.0135 \\
\hline 9 & 0.012 \\
\hline 10.5 & 0.016 \\
\hline 12 & 0.0159 \\
\hline 13.5 & 0.0234 \\
\hline 15 & 0.0262 \\
\hline 16.5 & 0.0228 \\
\hline 18 & 0.0185 \\
\hline 19.5 & 0.0222 \\
\hline 21 & 0.0223 \\
\hline 22.5 & 0.0001 \\
\hline 24 & 0.0191 \\
\hline 25.5 & 0.0228 \\
\hline
\end{tabular}

Table 2. Maximum Values of Vibration Data Collected for $2^{\text {nd }}$ Pile Point

\begin{tabular}{cc}
\hline $\begin{array}{c}\text { Depth } \\
(\mathbf{m})\end{array}$ & $\begin{array}{c}\mathbf{1}^{\text {st }} \text { accelerometer-Front Column (g) (12.53m } \\
\text { distance accelerometer to point of pile work) }\end{array}$ \\
\hline 1.5 & 0.0305 \\
\hline 3 & 0.0354 \\
\hline 4.5 & 0.0404 \\
\hline 6 & 0.0373 \\
\hline 7.5 & 0.0211 \\
\hline 9 & 0.0325 \\
\hline 10.5 & 0.0361 \\
\hline 12 & 0.0388 \\
\hline 13.5 & 0.0474 \\
\hline 15 & 0.0504 \\
\hline 16.5 & 0.0437 \\
\hline 18 & 0.0493 \\
\hline 19.5 & 0.045 \\
\hline 21 & 0.0555 \\
\hline 22.5 & 0.0445 \\
\hline 24 & 0.0371 \\
\hline 25.5 & 0.0445 \\
\hline
\end{tabular}

Table 3. Maximum Values of Vibration Data Collected for $3^{\text {rd }}$ Pile Point

\begin{tabular}{cc}
\hline $\begin{array}{c}\text { Depth } \\
(\mathbf{m})\end{array}$ & $\begin{array}{c}\mathbf{1}^{\text {st }} \text { accelerometer-Front Column (g) (7.11 m } \\
\text { distance accelerometer to point of pile work) }\end{array}$ \\
\hline 1.5 & 0.0366 \\
\hline 3 & 0.0288 \\
\hline 4.5 & 0.031 \\
\hline 6 & 0.0172 \\
\hline 7.5 & 0.0327 \\
\hline 9 & 0.0222 \\
\hline 10.5 & 0.0232 \\
\hline 12 & 0.0362 \\
\hline 13.5 & 0.0412 \\
\hline 15 & 0.0468 \\
\hline 16.5 & 0.0451 \\
\hline 18 & 0.0472 \\
\hline 19.5 & 0.0379 \\
\hline 21 & 0.0403 \\
\hline 22.5 & 0.0406 \\
\hline 24 & 0.0378 \\
\hline 25.5 & 0.0268 \\
\hline
\end{tabular}




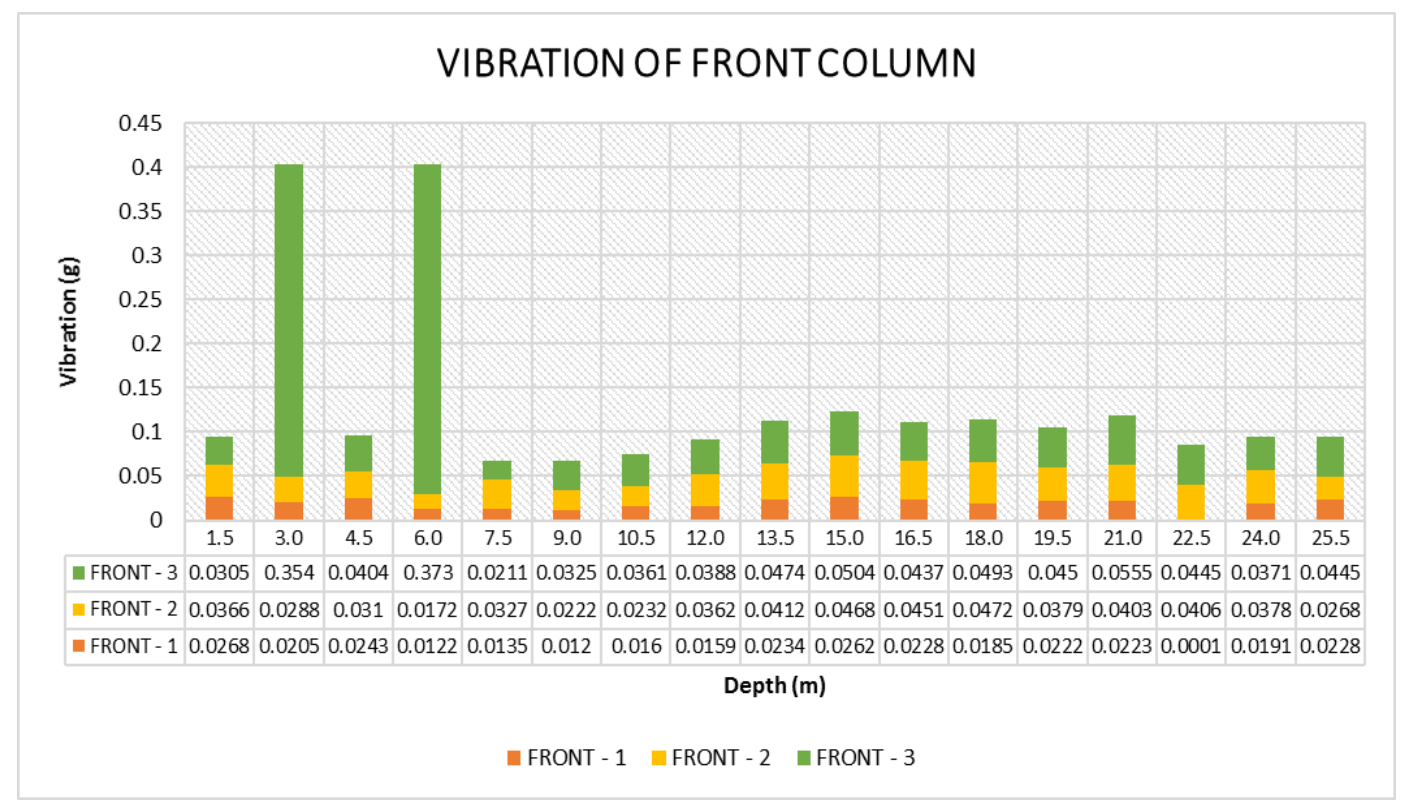

Figure 2. Vibration Value of Front Column

\subsection{Relationship between the Vibration and the Distance}

Based on Figure 2, for the front column, as the distance limits between pile points and column increases, the value of peak particle velocity is decreased. Therefore, this shows that the distance between pile points and the existing structure may affect the vibration level at the column or structure. This caused by the vibration waves that travel thru the soil will reduce little by little while traveling thru the soil. According to Abdel[10], vibration waves that were created from pile-driving are of high dangerous level and may give some damage to the surrounding buildings; however, the vibration level will greatly decrease as the distance between the pile-driving and source increases. The use of machineries in construction sites produces vibration waves. The sources of vibrations waves may come from blasting, compaction of soil and piling works. These vibration waves could directly or slightly affect and damage the existing nearby buildings.

Based on Table 4, the vibration data recorded can be compared with the guideline by referring to the row of Commercial (light and flexible structure) and column of $10-50 \mathrm{~Hz}$ at limits for continuous vibration box. It is justified that some of the data recorded from this project exceed the limits from BS5228. There are five data that exceed the limit which are $10.44 \mathrm{~mm} / \mathrm{s}, 10.351 \mathrm{~mm} / \mathrm{s}$, $10.889 \mathrm{~mm} / \mathrm{s}, 11.141 \mathrm{~mm} / \mathrm{s}, 12.260 \mathrm{~mm} / \mathrm{s}$. All the five data are in the front column. Therefore, the vibrations have affected the structure nearby with minor damage such as hair line crack and minor settlement at building apron nearby the column face. Furthermore, the value of peak particle of front column faces velocity decreased.

Table 4. Vibration Limits for Cosmetic Building Damage.[11]

\begin{tabular}{cccc}
\hline $\begin{array}{c}\text { Building type } \\
\text { (limits on } \\
\text { vibrations from } \\
\text { Eurocode 3 }\end{array}$ & $\begin{array}{c}\text { Press } \\
\text {-in }\end{array}$ & $\begin{array}{c}\text { 25kJ Drop } \\
\text { hammer }\end{array}$ & $\begin{array}{c}\text { 170kW } \\
\text { 27Hz vibro } \\
\text { hammer }\end{array}$ \\
\hline Architectural merit & $2.6 \mathrm{~m}$ & $29.6 \mathrm{~m}$ & $27.7 \mathrm{~m}$ \\
\hline Residential & $0.5 \mathrm{~m}$ & $11.8 \mathrm{~m}$ & $13.8 \mathrm{~m}$ \\
\hline Light Commercial & $0.14 \mathrm{~m}$ & $5.9 \mathrm{~m}$ & $5.5 \mathrm{~m}$ \\
\hline $\begin{array}{c}\text { Heavy } \\
\text { Commercial }\end{array}$ & $0.06 \mathrm{~m}$ & $3.9 \mathrm{~m}$ & $3.7 \mathrm{~m}$ \\
\hline Buried services & $0.03 \mathrm{~m}$ & $2.9 \mathrm{~m}$ & $2.2 \mathrm{~m}$ \\
\hline
\end{tabular}

Table 5 shows that piling work using drop hammer method; the distance limit between the piling points and the existing structure for light commercial buildings is only $5.9 \mathrm{~m}$. For this project, the least distance between the piling point and structure is $6.34 \mathrm{~m}$. Therefore, the distance is not over the limit based on Table 5 which summarises from Eurocode 3 and the distance is in the acceptable range. Thus, all the distances are acceptable and the chances for the building to have damage because of the distance are low. If there any damage happens to the existing structure in the future, the contractor can be safe from the blame since the distance between their piling points and the existing structure is acceptable. 
Table 5. Recommended Minimum Separations between Sensitive Building and Piling [11]

\begin{tabular}{lcccccc}
\hline \multicolumn{1}{c}{ Building Type } & \multicolumn{3}{c}{ Limit for Transient Vibration } & \multicolumn{2}{c}{ Limits for Continuous Vibration } \\
\cline { 2 - 7 } & $\mathbf{1 0 H z}$ & $\mathbf{1 0 - 5 0 H z}$ & $>\mathbf{5 0 H z}$ & $<\mathbf{1 0 H z}$ & $\mathbf{1 0 - 5 0 H z}$ & $>\mathbf{5 0 H z}$ \\
\hline \multicolumn{1}{c}{ Residential in Good Repair } & 5 & 10 & 20 & 2.5 & 5 & 10 \\
\hline $\begin{array}{l}\text { Residential with Significant Structural } \\
\text { Defects }\end{array}$ & 2.5 & 5 & 10 & 1.25 & 2.5 & 5 \\
\hline $\begin{array}{l}\text { Industrial/Commercial } \\
\text { flexible structure) }\end{array}$ & 10 & 20 & 40 & 5 & 10 & 20 \\
\hline $\begin{array}{l}\text { Industrial/Commercial (heavy and stiff } \\
\text { structure) }\end{array}$ & 15 & 30 & 60 & 7.5 & 15 & 30 \\
\hline
\end{tabular}

\section{Conclusions}

This study can give proper understanding and precaution to anyone involves in construction work especially piling works. They can predict and plan how much distance between the existing building and their piling work location should be considered to prevent from damaging the existing building. Besides, this study also can make as a guideline to industry to control vibrations which produce from their construction work especially piling works from damaging the existing building near their work location. It is found that the exact value of vibrations can affect the existing building near the piling work location. Besides, another finding knows the distance between piling work location and the existing building that can affect the building. Hence, the authority should be more sensitive to the terms of use of machinery such as piling installation machines. For an urban area, a hydraulic hammer piling machine should not be used because the hydraulic hammer piling machine will generate more vibration that can affect other buildings.

\section{Acknowledgments}

The authors acknowledge Universiti Teknologi MARA Pulau Pinang for the financial support. The authors are grateful to Geotechnical laboratory technician for the help in completing this research.

\section{REFERENCES}

[1] M. R. Svinkin,. Soil and structure vibrations from construction and industrial sources. Proc., Int. Conf. on Case Histories in Geotechnical Engineering, 1-14,2008.
[2] M. E. Bayraktar., Y. Kang, M. Svinkin, \& F. Arif Evaluation of Vibration Limits and Mitigation Techniques for Urban Construction, Florida Department of Transportation, Florida 2013.

[3] M.R. Svinkin, Minimizing Vibration Construction Effects, Journal of American Society Civil Engineering Vol. 9, 108-115. 2004.

[4] F. Deckner, K. Viking, \& S.Hintze, Vibration Transfer During Sheet Pile Driving - A Full-Scale Field Test. International Conference on Earthquake Geotechnical Engineering, 1-4 2015.

[5] H. Amick and M.Gandraeu, Construction Vibrations and Their Impact on Vibration-Sensitive Facilities, Journal of American Society of Civil Engineers Vol. 117, 22-26.2012.

[6] A. Z Adda, D.W. Richard, G. Athena, Effect of Pile Driving Induced Vibration on Nearby Structures and Other Assets. Final report. 73-78, 2013

[7] B. J. Mark, C. G. Michael, Ground Vibrations Associated with Installing Enlarged Base Driven Cast in Situ Piles. Journal of Australian Geomechanics.Vol.38, No.1, 67-73, 2002.

[8] E.B.Mehmet, K.Youngcheol, S.Mark, A.Farrukh A, Evaluation of Vibration Limits and Mitigation Techniques for Urban Construction. Florid Department of Transportation Research Center.2013.

[9] D.J Rockhill, M.D Bolton, D.J. White, Ground Borne Vibrations Due to Press in Piling Operations. Interantion Conference on Foundations, Innovations, observations, Design and Practice, 743-755,2014.

[10] S. M. Abdel Rahman, Vibration Associated with Pile Driving and its Effect in Nearby Historical Structures, In-proceeding-SPIE International Society Optical Engineering, 1251-1258, 2002

[11] British Standards Institution. Code of Practice for Noise and Vibration Control on Construction and Open Sites Part 2: Vibration. BS 5228-2:2009. 